\title{
PROPRIEDADES QUÍMICAS DO SOLO E NUTRIÇÃO DO EUCALIPTO EM FUNÇÃO DA APLICAÇÃO DE LODO DE ESGOTO(1)
}

\author{
Marcelino Carneiro Guedes ${ }^{(2)}$, Cristiano Alberto de Andrade ${ }^{(3)}$, F.ábio \\ Poggiani $^{(4)}$ \& Maria Emília Mattiazzo ${ }^{(5)}$
}

\begin{abstract}
RESUMO
A aplicação do lodo de esgoto em plantações florestais é uma das alternativas para resolver o problema da disposição final desse resíduo. O objetivo deste trabalho foi avaliar se a aplicação de biossólido melhora a fertilidade do solo e o estado nutricional de mudas de Eucalyptus grandis. O experimento foi montado em colunas de PVC de $20 \mathrm{~cm}$ de diâmetro, com nove tratamentos (testemunha, adubação mineral, doses crescentes de biossólido variando de 10 a $160 \mathrm{t} \mathrm{ha}^{-1}$ ) e quatro repetições. O experimento foi realizado durante 12 meses após o plantio das mudas. $\mathrm{O}$ biossólido influenciou mais a acidez do que outros atributos químicos do solo. Os teores de N, P e S nas folhas correlacionaram-se com a CTC e com o teor de C orgânico do solo, tendo essas variáveis apresentado valores significativamente mais elevados nas doses de 80 e $160 \mathrm{t} \mathrm{ha}^{-1}$. Observou-se diminuição da matéria orgânica do solo nas doses de 10 a $40 \mathrm{t} \mathrm{ha}^{-1}$. $\mathrm{O}$ biossólido alcalino diminui a acidez do solo e melhora sua fertilidade, aumentando a disponibilidade da maioria dos nutrientes.
\end{abstract}

Termos de indexação: Eucalyptus grandis, biossólido, carbono orgânico, acidez do solo, componentes principais.

\footnotetext{
${ }^{(1)}$ Recebido para publicação em abril de 2004 e aprovado em fevereiro de 2006.

(2) Pesquisador da Embrapa Amapa, Rd JK, km 05, CEP 68903-000 Macapá (AP). E-mail: mcguedes@cpafap.embrapa.br

(3) Pesquisador do Instituto Agronômico de Campinas - IAC. Av. Barão de Itapura 1481, Caixa Postal 28, CEP 13020-902 Campinas (SP). E-mail: andrade@iac.sp.gov.br

(4) Professor do Departamento de Ciências Florestais da Escola Superior de Agricultura "Luiz de Queiroz" - ESALQ/USP. Av. Pádua dias 11, Caixa Postal 09, CEP 13418-900 Piracicaba (SP). E-mail: fpoggian@esalq.usp.br

(5) Professora Aposentada do Departamento de Ciências Exatas, ESALQ/USP. E-mail: mmatiazzo@esalq.usp.br
} 


\title{
SUMMARY: SOIL CHEMICAL PROPERTIES AND EUCALYPT NUTRITION AS A FUNCTION OF SEWAGE SLUDGE ADDITION
}

\begin{abstract}
Sewage sludge application in forest plantations is one of the alternatives to solve the problematic final disposal of this residue. This research aimed at evaluating whether biosolids application improves soil fertility and the nutritional status of Eucalyptus grandis seedlings. The trial was installed in $20 \mathrm{~cm}$ diameter PVC columns with nine treatments (control, mineral fertilizer and increasing biosolid rates from 10 to $160 \mathrm{th}^{-1}$ ) in four replications. The experiment lasted 12 months after planting the seedlings. Biosolids had a greater influence on soil acidity than on the other soil chemical properties. N, Pand S leaf concentrations were correlated with CEC and soil organic $C$ content. These variables presented significantly higher values at doses of 80 and $160 \mathrm{th} \mathrm{h}^{-1}$. It was observed that soil

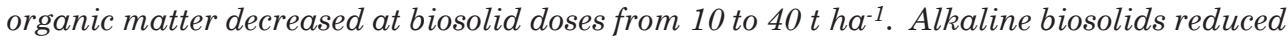
the soil acidity and improved soil fertility, increasing the availability of most nutrients.
\end{abstract}

Index terms: Eucalyptus grandis, biosolid, organic carbon, soil acidity, principal components.

\section{INTRODUÇÃO}

A utilização de lodo de esgoto como biossólido, aproveitando seu potencial fertilizante e condicionador de solos para promover o crescimento de plantas, representa a possibilidade de associar ganhos para o produtor, por meio do aumento da produtividade das culturas e redução do uso de fertilizantes minerais, com ganhos para os geradores de lodo, pela efetivação de métodos adequados e mais econômicos de disposição final desse resíduo. Segundo Matthews (1998), o futuro da disposição de lodo deverá ser, predominantemente, a incineração ou o uso como biossólido.

Corrêa \& Corrêa (2001) valoraram o biossólido como fonte de N, P e matéria orgânica, utilizando o método de "mercado de bens substitutos". Segundo esses autores, o valor do lodo úmido atingiu $\mathrm{R} \$ 22,00$ a tonelada. A secagem térmica foi o processo de estabilização que mais agregou valor ao produto, atingindo $\mathrm{R} \$ 158,60$ a tonelada. Apesar do potencial valor fertilizante do biossólido, não se deve esquecer de que este é um resíduo do processo de tratamento dos esgotos, cuja disposição final é responsabilidade da unidade geradora. Assim, a conversão do potencial fertilizante de biossólidos em valor monetário é inadequada, uma vez que o resíduo não deve ter preço e ser comercializado. Deixar o status de resíduo e passar a ser considerado subproduto ou matéria-prima é passo futuro, na medida em que resultados de pesquisas confirmem que os biossólidos não causam danos ao meio ambiente e à saúde humana. Afirmar isso, atualmente, no Brasil, seria prematuro, frente, principalmente, ao fato de ainda serem incipientes as pesquisas em território nacional, à elevada variabilidade que existe nos lodos gerados em diferentes estações e à ausência de uma legislação federal específica que regulamente a utilização do biossólido.
A pesquisa brasileira com uso de biossólidos na agricultura foi iniciada na década de oitenta. Bettiol \& Carvalho (1982) foram os primeiros pesquisadores brasileiros a publicarem sobre a utilização de lodo de esgoto na agricultura. O surgimento das pesquisas na área florestal ainda é fato mais recente. Em 1998, um grupo de pesquisadores da ESALQ/USP iniciou as primeiras pesquisas de campo sobre a aplicação de biossólidos em culturas florestais no Brasil. O trabalho de Poggiani \& Bennedeti (1999) resume o programa de pesquisa desse grupo e mostra os vários subprojetos que foram desenvolvidos para verificar a viabilidade ecológica, silvicultural e econômica da utilização do biossólido em cultura de eucalipto.

Segundo Smith \& Carnus (1997), a aceitação internacional da utilização de biossólidos em florestas aumentou ao longo das últimas décadas graças aos numerosos resultados de campo que viabilizaram o desenvolvimento de uma forte base teórica e prática para sistemas de aplicação ambientalmente aceitáveis, bem como às várias publicações que permitiram a organização do planejamento e do esquema da aplicação. A cidade de Bremerton, no estado de Washington, vem aplicando biossólido em florestas desde o início da década de setenta, tendo sido, no ano de 1997, $100 \%$ do biossólido destinado às florestas do próprio município (Leonard \& McKinney, 1997).

De maneira geral, tanto na América do Norte, quanto na Europa e na Austrália, existem diversas pesquisas com respostas favoráveis das espécies florestais de interesse silvicultural ao uso de biossólido, principalmente do gênero Pinus (McNab \& Berry, 1985; Phillips et al., 1986; Hart et al., 1988; Weetman et al., 1993; Henry et al., 1993, 1994; Polglase \& Myers, 1995; Kaposts et al., 2000).

Em relação à cultura de eucalipto, foram encontradas poucas referências na literatura 
internacional, publicadas em países como Austrália, Nova Zelândia e Egito. No Egito, El-Baha (2001) encontrou efeito positivo do biossólido sobre o crescimento de Eucalyptus camaldulensis. No Brasil, o grupo de pesquisadores da ESALQ/USP é, atualmente, o único que vem pesquisando e publicando sobre a utilização de biossólidos em plantio de eucalipto.

Guedes \& Poggiani (2003) estudaram, em condições de campo, o efeito do biossólido produzido na estação de tratamento de esgoto (ETE) de Barueri (SP), onde o lodo é tratado/estabilizado com cal e cloreto férrico sobre a ciclagem de nutrientes, e verificaram alterações significativas nos teores de nutrientes nas folhas das árvores de eucalipto que receberam o produto. No mesmo experimento, Vaz \& Gonçalves (2002) observaram significativas alterações na fertilidade do solo devido à aplicação do biossólido. No trabalho de Melo et al. (2001), foi citado que outros autores, trabalhando com diferentes biossólidos, em diferentes condições e culturas, também detectaram efeito da aplicação do lodo sobre a fertilidade de solos e nutrição de plantas. No entanto, existem na literatura várias contradições em relação ao efeito do biossólido sobre as características do solo e sobre a disponibilidade de nutrientes às plantas. Um exemplo é o efeito de aumento (Harrison et al., 1994; Oliveira et al., 2002, Simonete, 2003) ou redução (Terry, 1979; Hsieh et al., 1981; Vaz \& Gonçalves, 2002; Soares, 2003) dos teores de C orgânico em solos tratados com biossólidos.

Baseado na hipótese de que o biossólido pode ser utilizado como fertilizante para a cultura de eucalipto, desenvolveu-se o presente trabalho com o objetivo de avaliar se a aplicação de biossólido melhora as propriedades químicas do solo e favorece a absorção de nutrientes por plantas de Eucalyptus grandis em fase de crescimento inicial.

\section{MATERIAL E MÉTODOS}

\section{Instalação do experimento}

O experimento foi montado, a céu aberto, no viveiro do Departamento de Ciências Florestais da Escola Superior de Agricultura "Luiz de Queiroz", município de Piracicaba (SP). Foram utilizadas colunas de PVC rígido com $20 \mathrm{~cm}$ de diâmetro e $100 \mathrm{~cm}$ de altura, sendo cada coluna dividida em três anéis. Os dois anéis inferiores tinham $30 \mathrm{~cm}$ de altura e o superior $40 \mathrm{~cm}$, sobrando $10 \mathrm{~cm}$ de borda superior para evitar possíveis perdas de material. As colunas foram montadas preenchendo os anéis com a terra coletada nas diferentes profundidades de um Latossolo Vermelho-Amarelo. As colunas foram fixadas sobre suportes que as mantiveram elevadas, possibilitando drenagem e coleta do lixiviado. Antes do preenchimento dos anéis, suas paredes internas foram revestidas com uma espuma à base de difenilmetano dissocianato, para tornar a superfície rugosa, evitando a criação de uma via preferencial de drenagem pela superfície lateral dos tubos.

As mudas de Eucalyptus grandis foram plantadas em fevereiro de 1999, 40 dias após incorporação do biossólido ao solo, e o ensaio foi realizado durante doze meses após o plantio.

\section{Dados climáticos do período experimental}

Os dados sobre precipitação pluviométrica e temperatura média mensal apresentados (Figura 1) foram extraídos do endereço eletrônico http:// www.ciagri.usp.br/ emdabreu/MEDIAS.TXT, em 07 de fevereiro de 2003. Essa página é mantida pelo Departamento de Ciências Exatas, da Escola Superior de Agricultura "Luiz de Queiroz", que gerencia a estação meteorológica da ESALQ, localizada, aproximadamente, a $500 \mathrm{~m}$ do local onde foi instalado o experimento.

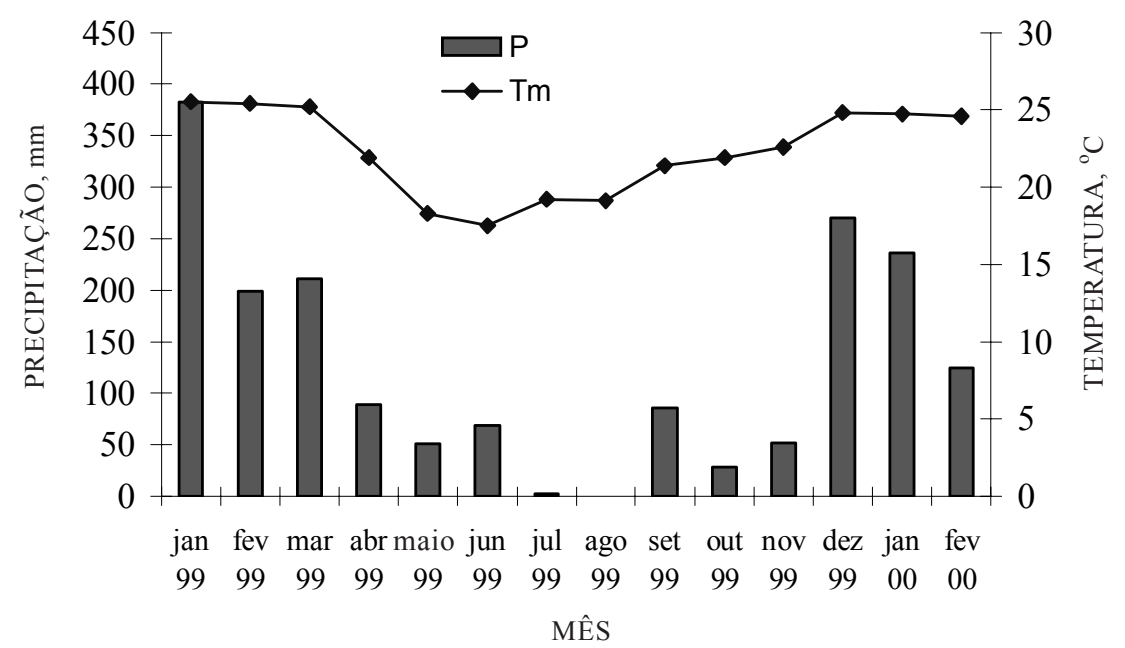

Figura 1. Valores mensais da precipitação pluvial acumulada (P) e da temperatura média (Tm) durante o período experimental de janeiro de 1999 (jan. 99) a fevereiro de 2000 (fev. 00). 


\section{Solo}

Foi utilizada amostra de um Latossolo VermelhoAmarelo distrófico de textura média, proveniente da Estação Experimental de Itatinga (SP), vinculada ao Departamento de Ciências Florestais da ESALQ/ USP. Esse tipo de solo é representativo de extensas áreas sob cultivo com eucalipto no Estado de SP. As amostras de terra foram coletadas em três profundidades $(0-30 ; 30-60 ; 60-90 \mathrm{~cm})$, para posterior remontagem nas colunas de PVC, após peneiramento em malha de $4 \mathrm{~mm}$. O quadro 1 mostra a caracterização do solo original, realizada por Andrade (1999). Cabe ressaltar que a terra foi coletada em um solo de baixa fertilidade natural, de uma área mantida sob seguidas rotações de Eucalyptus saligna cultivado sem qualquer reposição dos nutrientes via adubação, o que resultou em valores extremamente baixos de $\mathrm{P}, \mathrm{K}, \mathrm{Ca}$ e $\mathrm{Mg}$.

\section{Biossólido}

O material proveniente da estação de tratamento de esgoto de Barueri (SP) foi seco ao ar e peneirado em malha de $4 \mathrm{~mm}$. O biossólido foi produzido após tratamento biológico dos esgotos (digestão aeróbia, utilizando ar difuso durante a fase de decantação, e digestão anaeróbia do lodo primário e do secundário), seguido de condicionamento químico com $\mathrm{FeCl}_{3}$ e $\mathrm{Ca}(\mathrm{OH})_{2}$, para posterior desaguamento na fase final. Esse tipo de tratamento origina um biossólido que apresenta $\mathrm{pH}$ elevado e altos teores de $\mathrm{Ca}$ e Fe. A caracterização do biossólido (Quadro 2) foi realizada no laboratório de Química Ambiental da ESALQ, segundo método proposto por Eaton et al. (1995).

\section{Delineamento experimental e tratamentos}

A instalação do experimento seguiu o delineamento experimental totalmente casualizado, com nove tratamentos e quatro repetições
Quadro 2. Características químicas do biossólido utilizado (resultados em base seca)

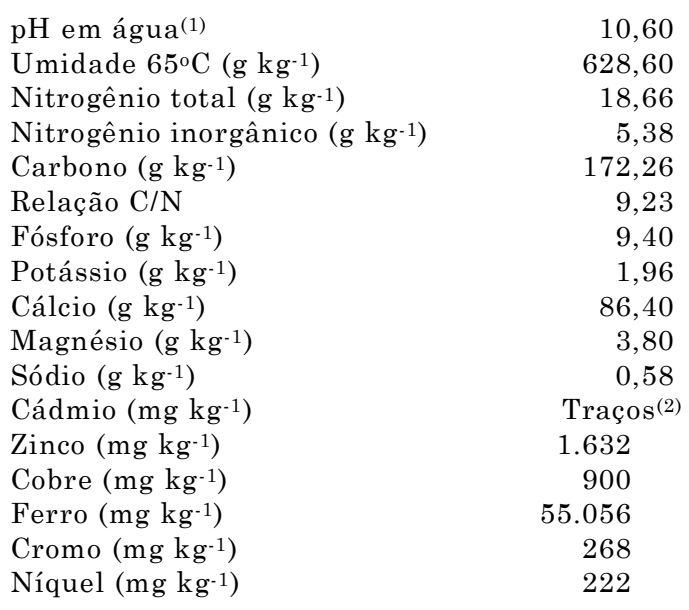

${ }^{(1)}$ Determinado a partir do material original. ${ }^{(2)}$ Abaixo do limite de determinação analítica do método utilizado.

(Quadro 3), totalizando trinta e seis unidades experimentais.

A adubação mineral referente ao tratamento T2 foi realizada da seguinte maneira:

- aos 20 dias que precederam o plantio, aplicou-se, em superfície, o equivalente a 1,5 t ha ${ }^{-1}$ de calcário dolomítico;

- no plantio, foram aplicados o equivalente a $15 \mathrm{~kg} \mathrm{ha}^{-1} \mathrm{de} \mathrm{N}+80 \mathrm{~kg} \mathrm{ha}^{-1}$ de P $+15 \mathrm{~kg} \mathrm{ha}^{-1}$ de K (via solução de $\left(\mathrm{NH}_{4}\right) \mathrm{H}_{2} \mathrm{PO}_{4} ; \mathrm{Ca}\left(\mathrm{H}_{2} \mathrm{PO}_{4}\right)_{2} \cdot \mathrm{H}_{2} \mathrm{O}$ e $\mathrm{KCl}$;

- aos 65 dias do plantio, aplicaram-se $15 \mathrm{~kg} \mathrm{ha}^{-1} \mathrm{de}$ $\mathrm{N}+15 \mathrm{~kg} \mathrm{ha}{ }^{-1}$ de $\mathrm{K}$ (via solução de $\left(\mathrm{NH}_{4}\right)_{2} \mathrm{SO}_{4} \mathrm{e}$ $\mathrm{KCl}$;

Quadro 1. Caracterização das amostras do Latossolo Vermelho-Amarelo em três profundidades de coleta

\begin{tabular}{|c|c|c|c|c|c|c|c|c|c|c|c|c|}
\hline Profundidade & pH & MO & $P$ resina & $\mathbf{K}^{+}$ & $\mathbf{C a}^{2+}$ & $\mathbf{M g}^{2+}$ & $\mathrm{H}+\mathrm{Al}$ & $\mathrm{Al}^{3+}$ & SB & СтC & V & \\
\hline $\mathrm{cm}$ & $\mathrm{CaCl}_{2}$ & $\mathrm{~g} \mathrm{dm}^{-3}$ & $\mathrm{mg} \mathrm{dm} \mathrm{m}^{-3}$ & \multicolumn{7}{|c|}{$-\mathrm{mmol}_{\mathrm{c}} \mathrm{dm}^{-3}$} & \multicolumn{2}{|c|}{ — $\%$} \\
\hline $0-30$ & 4,0 & 16 & 1 & 1,2 & 1 & 1 & 34,0 & 7 & 3 & 37 & 9 & \\
\hline $30-60$ & 4,0 & 15 & 1 & 0,5 & 1 & 1 & 31,0 & 6 & 3 & 34 & 7 & \\
\hline \multirow[t]{3}{*}{$60-90$} & 4,1 & 14 & 1 & 0,3 & 1 & 1 & 28,0 & 5 & 2 & 30 & 8 & \\
\hline & & \multicolumn{11}{|c|}{ Granulometria } \\
\hline & & \multicolumn{2}{|c|}{ Argila } & \multicolumn{3}{|c|}{ Silte } & \multicolumn{3}{|c|}{ Areia fina } & \multicolumn{3}{|c|}{ Areia grossa } \\
\hline $0-30$ & \multicolumn{3}{|c|}{168} & \multicolumn{3}{|c|}{59} & \multicolumn{3}{|c|}{241} & \multicolumn{3}{|c|}{532} \\
\hline $30-60$ & \multirow{2}{*}{\multicolumn{3}{|c|}{190}} & \multirow{2}{*}{\multicolumn{3}{|c|}{$\begin{array}{l}49 \\
29\end{array}$}} & \multirow{2}{*}{\multicolumn{3}{|c|}{$\begin{array}{l}266 \\
278\end{array}$}} & \multirow{2}{*}{\multicolumn{3}{|c|}{495}} \\
\hline $60-90$ & & & & & & & & & & \multicolumn{2}{|r|}{496} & \\
\hline
\end{tabular}


Quadro 3. Caracterização dos tratamentos experimentais

\begin{tabular}{ccc} 
Tratamento & $\begin{array}{c}\text { Biossólido(1) } \\
\left(\mathbf{t ~ h a}^{-1}\right)\end{array}$ & $\begin{array}{c}\text { Adubação } \\
\text { mineral }\end{array}$ \\
\hline T1 & 0 & - \\
T2 & 0 & Completa \\
T3 & 10 & $70,4 \mathrm{~kg} \mathrm{ha}^{-1} \mathrm{~K}$ \\
T4 & 20 & $50,8 \mathrm{~kg} \mathrm{ha}^{-1} \mathrm{~K}$ \\
T5 & 40 & $11,6 \mathrm{~kg} \mathrm{ha}^{-1} \mathrm{~K}$ \\
T6 & 40 sem planta & $11,6 \mathrm{~kg} \mathrm{ha}^{-1} \mathrm{~K}$ \\
T7 & 40 aplicação superficial & $11,6 \mathrm{~kg} \mathrm{ha}^{-1} \mathrm{~K}$ \\
T8 & 80 & - \\
T9 & 160 & - \\
\hline
\end{tabular}

(1) Doses em base seca.

- aos 120 dias do plantio, foram aplicados $15 \mathrm{~kg} \mathrm{ha}^{-1}$ de $\mathrm{N}+60 \mathrm{~kg} \mathrm{ha}^{-1}$ de $\mathrm{K}$ (via solução de $\left(\mathrm{NH}_{4}\right)_{2} \mathrm{SO}_{4}$ e $\mathrm{KCl}),+\mathrm{B}$ e $\mathrm{Zn}$.

A complementação com $\mathrm{K}$ mineral ( $\mathrm{KCl}, 60 \%$ de $\mathrm{K}_{2} \mathrm{O}$ ) nos tratamentos com biossólido foi necessária porque o teor desse elemento no resíduo mostrou-se baixo, assim como no solo usado no experimento. $\mathrm{O}$ $\mathrm{KCl}$ foi adicionado de modo a atingir, em todos os tratamentos, a quantidade que foi colocada no tratamento T2 (90 kg ha-1). Desse modo, com o aumento da dose de biossólido, adicionou-se menos $\mathrm{K}$ mineral; as doses de 80 e $160 \mathrm{t} \mathrm{ha}^{-1}$ não necessitaram do complemento. A complementação foi dividida em duas aplicações, uma no plantio e outra 65 dias após. Aos 120 dias do plantio, foram adicionados mais $40 \mathrm{~kg} \mathrm{ha}^{-1}$ de $\mathrm{K}_{2} \mathrm{O}$ em todos os tratamentos, menos na testemunha e no tratamento $\mathrm{T} 2$, em razão dos sintomas visuais de deficiência desse elemento apresentados pelas plantas.

Quarenta dias antes do plantio das mudas, o biossólido foi incorporado à camada superficial (0$30 \mathrm{~cm}$ ) em todos os tratamentos, exceto no tratamento $\mathrm{T} 7$, em que houve apenas aplicação superficial.

\section{Coleta e análises laboratoriais das amostras}

O experimento foi finalizado doze meses após o plantio das mudas. Cada planta de eucalipto foi cortada rente ao solo e teve sua altura determinada. A fitomassa epígea constituinte de cada planta foi coletada e separada em folhas com seus respectivos pecíolos e em caule + ramos. Esse material foi seco em estufa de ventilação forçada a $65^{\circ} \mathrm{C}$ até peso constante e teve a fitomassa seca determinada. Após a determinação da fitomassa, o material foi processado em moinho tipo Wiley (malha 20 mesh). Foram analisados os elementos N, P, K, Ca, Mg, S, $\mathrm{B}, \mathrm{Fe}, \mathrm{Zn}, \mathrm{Mn}$ e $\mathrm{Cu}$, contidos no material vegetal após digestão sulfúrica $(\mathrm{N})$ e nítrico-perclórica (demais elementos), nos laboratórios do
Departamento de Solos, da Escola Superior de Agricultura "Luiz de Queiroz". O P foi determinado por colorimetria, o teor de $\mathrm{N}$ total, pelo método microKjeldhal; de K por fotometria de chama; de S, por turbidimetria, e dos demais elementos, por espectrofotometria de absorção atômica, segundo Malavolta et al. (1997).

Após desmontadas as colunas, as raízes foram separadas e amostras de terra da camada superficial $(0-30 \mathrm{~cm})$ foram coletadas. Nas colunas do tratamento em que o biossólido foi aplicado superficialmente, o material ainda visível, que não tinha sido incorporado ao solo, foi descartado. As amostras foram secas em estufas de ventilação forçada a $40^{\circ} \mathrm{C}$, passadas em peneiras de $2 \mathrm{~mm}$ e foram submetidas à análise de rotina para avaliação da fertilidade, conforme Raij et al. (1987).

\section{Análises dos dados}

Foi realizada uma análise de componentes principais seguida por um procedimento de rotação pela máxima variância. As múltiplas variáveis dependentes referentes à fertilidade do solo foram agrupadas em componentes principais, combinações lineares das variáveis originais, assim como os teores dos nutrientes nas folhas do eucalipto. Os "escores" dos componentes foram submetidos à análise de correlação para verificar a dependência entre os nutrientes nas plantas e as variáveis do solo. Para comparar o efeito dos tratamentos sobre alguma variável específica, foram realizadas análises de variância e interpretados os intervalos de confiança para as médias de cada tratamento, sendo consideradas estatisticamente significativas as diferenças entre médias cujos intervalos eram mutuamente excludentes. Todas as análises utilizaram o software Statistica.

\section{RESULTADOS E DISCUSSÃO}

\section{Crescimento do eucalipto}

Não foram detectadas diferenças estatisticamente significativas $(\mathrm{p}=0,090)$, a $5 \%$, durante a análise das variâncias das alturas das plantas cultivadas em cada tratamento (Figura 2).

A deficiência de $\mathrm{K}$, cujos sintomas visuais foram observados quatro meses após o plantio, pode ter comprometido o crescimento das mudas e atenuado o efeito dos tratamentos sobre a altura. Quando considerada a fitomassa de folhas como variável resposta, a análise de variância mostrou diferenças significativas $(\mathrm{p}=0,005)$ entre os tratamentos (Figura 3).

$\mathrm{O}$ eucalipto do tratamento $\mathrm{T} 3$, que recebeu $10 \mathrm{t} \mathrm{ha}^{-1}$ de biossólido, apresentou a mesma quantidade de fitomassa foliar do que na testemunha 


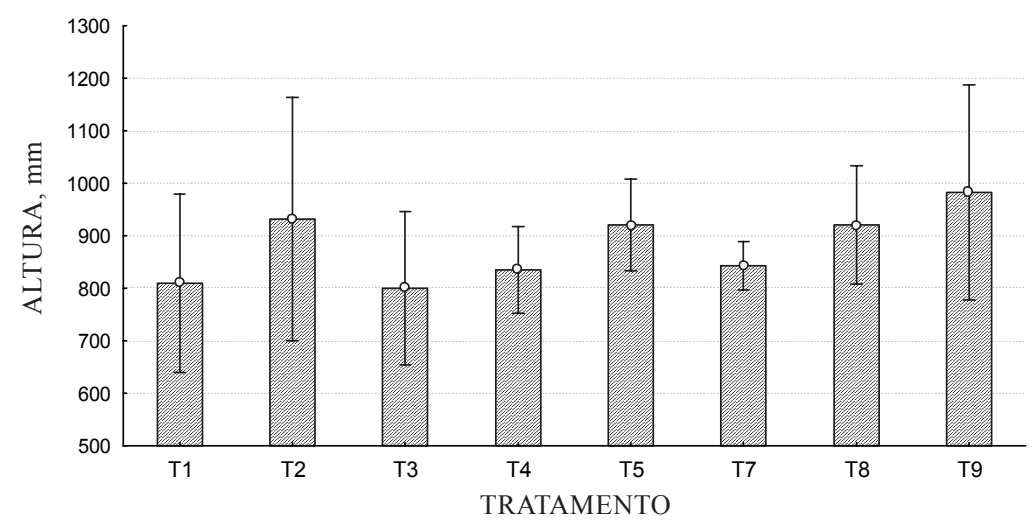

Figura 2. Média $(n=4)$ da altura do eucalipto aos 12 meses de idade em cada tratamento. A variação é o Intervalo de Confiança calculado com $95 \%$ de certeza.

T1-testemunha; T2-adubação mineral; T3-10 t ha ${ }^{-1}$ de biossólido $+\mathrm{K}$ mineral; T4-20 t ha ${ }^{-1}$ de biossólido + K mineral; T5-40 t ha-1 de biossólido + K mineral; T7-40 t ha ${ }^{-1}$ de biossólido + K mineral, aplicação superficial; T8-80 t ha-1 de biossólido; T9-160 t ha-1 de biossólido.

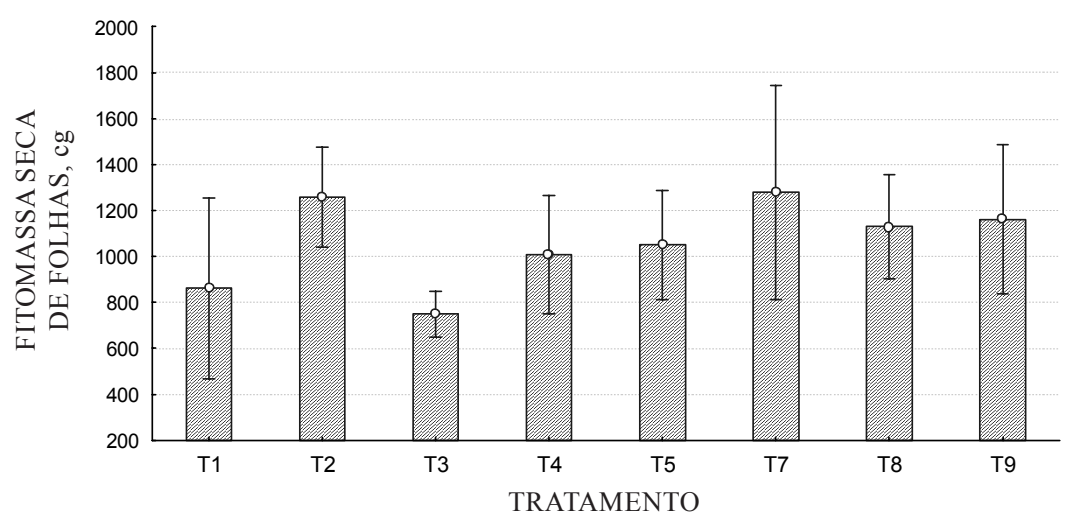

Figura 3. Média $(n=4)$ da produção de folhas pelo eucalipto com um ano de idade em cada tratamento. A variação é o Intervalo de Confiança calculado com 95 \% de certeza.

T1-testemunha; T2-adubação mineral; T3-10 t ha ${ }^{-1}$ de biossólido $+\mathrm{K}$ mineral; T4-20 t ha ${ }^{-1}$ de biossólido $+\mathrm{K}$ mineral; T5-40 t ha ${ }^{-1}$ de biossólido + K mineral; T7-40 t ha ${ }^{-1}$ de biossólido + K mineral, aplicação superficial; T8-80 t ha-1 de biossólido; T9-160 t ha-1 de biossólido.

e menos fitomassa do que os outros tratamentos. Esse efeito pode ter sido ocasionado pelos menores teores de $\mathrm{C}$ e $\mathrm{P}$ no solo (Quadro 4), observados nas colunas onde foi aplicada a dose de $10 \mathrm{t} \mathrm{ha}^{-1}$.

\section{Fertilidade do solo}

A análise de componentes principais das variáveis respostas do solo mostrou uma clara inflexão após a retenção do terceiro componente. Em conjunto, os três primeiros componentes principais, extraídos das onze variáveis originais referentes à fertilidade do solo, conseguem explicar $92 \%$ da variação total (Quadro 5), justificando a retenção e análise apenas desses três componentes.

O primeiro componente é sempre o mais importante, neste caso, conseguindo explicar $60 \%$ da variação nos dados originais em função dos tratamentos aplicados e do erro aleatório. O quadro 6 mostra quais variáveis foram significativas na formação dos componentes. O valor dos coeficientes, em módulo, é diretamente proporcional à importância de cada variável no componente.

$\mathrm{O}$ primeiro componente relaciona as variáveis $\mathrm{pH}$, $\mathrm{Ca}^{2+}, \mathrm{Al}^{3+}, \mathrm{H}+\mathrm{Al}, \mathrm{SB}$ e V \% e pode ser interpretado como uma resposta relacionada com a acidez do solo. As variáveis $\mathrm{Al}^{3+}$ e $\mathrm{H}+\mathrm{Al}$ são negativamente relacionadas com as outras, indicando que o efeito do fator de variação sobre elas proporciona a diminuição de seus valores, enquanto os valores das outras variáveis aumentam. A interpretação simultânea para as variáveis do componente mostra que os tratamentos-testemunha e adubação não diferem entre si e apresentam diferenças significativas de todos os outros que receberam biossólido. De maneira geral, a terra que recebeu biossólido apresentou maiores valores de $\mathrm{pH}, \mathrm{Ca}^{2+}$, $\mathrm{SB}$ e V \%, assim como menores valores de $\mathrm{Al}^{3+}$ e de $\mathrm{H}+\mathrm{Al}$. Vários trabalhos confirmam o efeito de biossólidos alcalinos no aumento do $\mathrm{pH}$ e diminuição do $\mathrm{Al}^{3+}$ e da acidez potencial (Sloan \& Basta, 1995; Silva et al., 1998; Christie et al., 2001, Oliveira et al., 
Quadro 4. Em negrito, valores médios $(\mathrm{n}=4)$ de resultados da análise de fertilidade do solo na camada de 0$30 \mathrm{~cm}$. Abaixo da média encontram-se os intervalos calculados com $95 \%$ de confiança.

\begin{tabular}{|c|c|c|c|c|c|c|c|c|c|c|c|}
\hline & $\mathbf{p H}$ & C & $\mathbf{P}$ & $\mathbf{K}^{+}$ & $\mathrm{Ca}^{2+}$ & $\mathbf{M g}^{2+}$ & $\mathrm{Al}^{3+}$ & $\mathbf{H}+\mathbf{A l}$ & SB & CTC & V \\
\hline & $\mathrm{CaCl}_{2}$ & $\mathrm{~g} \mathrm{~kg}^{-1}$ & $\mathrm{mg} \mathrm{dm}-3$ & & & $=$ & $\mathrm{mol}_{\mathrm{c}} \mathrm{dm}$ & & & & $\%$ \\
\hline \multirow[t]{2}{*}{$\mathrm{T} 1$} & 3,7 & 10,5 & 4,0 & 0,6 & 0,7 & 0,2 & 1,2 & 5,0 & 1,0 & 6,0 & 17 \\
\hline & $3,5-3,9$ & $3,7-17,2$ & $1,1-6,9$ & $0,4-0,7$ & $0,3-1,2$ & $0,1-0,4$ & $0,6-1,7$ & $2,5-7,5$ & $0,4-1,6$ & $2,9-9,1$ & $14-20$ \\
\hline \multirow[t]{2}{*}{$\mathrm{T} 2$} & 3,9 & 10,1 & 18,6 & 0,6 & 1,1 & 0,4 & 0,7 & 4,1 & 1,5 & 5,6 & 27 \\
\hline & $3,7-4,1$ & $3,8-16,4$ & $5,4-31,7$ & $0,3-0,8$ & $0,7-1,5$ & $0,3-0,5$ & $0,4-1,0$ & $1,9-6,4$ & $1,0-2,0$ & $3,0-8,3$ & $21-33$ \\
\hline \multirow[t]{2}{*}{ T3 } & 4,3 & 8,8 & 7,6 & 0,7 & 1,8 & 0,2 & 0,4 & 2,8 & 2,1 & 4,9 & 44 \\
\hline & $4,2-4,3$ & $7,3-10,3$ & $6,4-8,8$ & $0,4-0,9$ & $1,6-1,9$ & $0,2-0,3$ & $0,4-0,4$ & $1,4-4,2$ & $1,9-2,3$ & $3,6-6,1$ & $28-58$ \\
\hline \multirow{2}{*}{$\mathrm{T} 4$} & 4,9 & 7,4 & 10,1 & 0,4 & 2,7 & 0,2 & 0,1 & 1,8 & 3,0 & 4,7 & 64 \\
\hline & $4,5-5,3$ & $3,1-11,7$ & $7,5-12,8$ & $0,3-0,5$ & $2,3-3,1$ & $0,2-0,3$ & $0,1-0,1$ & $0,4-3,1$ & $2,6-3,4$ & $3,1-6,4$ & $49-79$ \\
\hline \multirow[t]{2}{*}{ T5 } & 5,7 & 5,7 & 14,3 & 0,3 & 4,3 & 0,2 & 0,0 & 0,8 & 4,6 & 5,4 & 84 \\
\hline & $5,5-6,0$ & $4,7-6,6$ & $9,4-19,2$ & $0,3-0,3$ & $3,0-5,6$ & $0,2-0,3$ & - & $0,4-1,2$ & $3,3-5,8$ & $4,0-6,8$ & $77-92$ \\
\hline \multirow[t]{2}{*}{$\mathrm{T} 6$} & 5,9 & 7,8 & 29,7 & 0,6 & 7,3 & 0,4 & 0,0 & 1,0 & 7,7 & 8,7 & 89 \\
\hline & $5,3-6,5$ & $3,8-11,8$ & $21,7-37,5$ & $0,3-0,8$ & $1,6-12,9$ & $0,2-0,5$ & - & $0,2-1,8$ & $1,9-13,5$ & $2,2-15,1$ & $82-95$ \\
\hline \multirow[t]{2}{*}{$\mathrm{T} 7$} & 4,8 & 11,7 & 25,1 & 0,5 & 3,5 & 0,3 & 0,2 & 2,6 & 3,8 & 6,4 & 60 \\
\hline & $4,2-5,4$ & $4,2-19,3$ & $14,6-35,5$ & $0,3-0,6$ & $1,6-5,4$ & $0,2-0,3$ & $0,1-0,5$ & $0,9-4,3$ & $1,8-5,8$ & $2,6-10,1$ & $56-64$ \\
\hline \multirow[t]{2}{*}{ T8 } & 6,0 & 11,3 & 51,6 & 0,5 & 10,1 & 0,3 & $\mathbf{0 , 0}$ & 0,8 & 10,5 & 11,3 & 93 \\
\hline & $5,5-6,4$ & $9,1-13,6$ & $28,1-75,1$ & $0,3-0,6$ & $7,7-12,5$ & $0,3-0,4$ & - & $0,5-1,1$ & $8,1-12,9$ & $9,1-13,4$ & $89-97$ \\
\hline \multirow[t]{2}{*}{ T9 } & 6,1 & 15,1 & 73,6 & 0,4 & 10,5 & 0,4 & 0,0 & 0,8 & 10,9 & 11,7 & 93 \\
\hline & $5,7-6,4$ & $11,4-18,8$ & $35,5-111$, & $0,4-0,4$ & $7,3-13,6$ & $0,3-0,5$ & - & $0,6-0,9$ & $7,7-14,1$ & $8,5-14,8$ & $90-96$ \\
\hline
\end{tabular}

Tratamentos: T1-testemunha; T2-adubação mineral; T3-10 t ha ${ }^{-1}$ de biossólido + K mineral; T4-20 t ha-1 de biossólido + K mineral; $\mathrm{T} 5-40 \mathrm{t} \mathrm{ha}^{-1}$ de biossólido $+\mathrm{K}$ mineral; T6-40 t ha ${ }^{-1}$ de biossólido $+\mathrm{K}$ mineral, sem planta; T7-40 t ha ${ }^{-1}$ de biossólido $+\mathrm{K}$ mineral, aplicação superficial; T8-80 t ha ${ }^{-1}$ de biossólido; T9-160 t ha ${ }^{-1}$ de biossólido.

Quadro 5. Autovalores e proporção da variância total explicada pelos três componentes principais originados das onze variáveis referentes à fertilidade do solo

\begin{tabular}{ccccc}
\hline Componente & Autovalor & Autovalor acumulado & \% da variância total & \% acumulada \\
\hline 1 & 6,580699 & 6,58070 & 59,82453 & 59,82453 \\
2 & 2,910662 & 9,49136 & 26,46056 & 86,28510 \\
3 & 0,588713 & 10,08007 & 5,35194 & 91,63703 \\
\hline
\end{tabular}

2002). Tal efeito deve-se, provavelmente, à alcalinidade intrínseca a esse tipo de material $(\mathrm{pH}$ em média > 10), função da adição de elevadas quantidades de $\mathrm{CaO}$ durante a fase de condicionamento químico nas estações de tratamento de esgotos (Oliveira et al., 2002).

Por outro lado, biossólidos que não recebem o referido tipo de condicionamento podem também apresentar efeito neutralizante (Bramryd, 2001), bem como, em outros casos, exibir efeito acidificante (Dowdy et al., 1991; Harrison et al., 1994; Dahlim et al., 1997; Sui \& Thompson, 2001, Simonete et al., 2003). Os autores atribuem o efeito acidificante dos biossólidos às reações de nitrificação, oxidação de sulfitos e produção de ácidos orgânicos.
O segundo componente relaciona as variáveis $\mathrm{C}$, $\mathrm{P}, \mathrm{Ca}^{2+}, \mathrm{Mg}^{2+}, \mathrm{SB}$ e CTC (Quadro 6), mostrando que essas variáveis apresentam o mesmo padrão de variação conforme os tratamentos aplicados. Esse componente pode ser interpretado como um fator mais relacionado com a fertilidade e matéria orgânica do solo. A CTC e o C orgânico do solo foram as variáveis mais importantes na formação do Componente 2. Os tratamentos influenciaram em maior grau a acidez do que os demais atributos do solo. A variável $\mathrm{K}^{+}$foi a única responsável pela formação do terceiro componente, mas já em um grau inferior de importância, pois explicou apenas $5 \%$ da variância, indicando que esse nutriente foi pouco afetado pelos tratamentos e que não houve correlação entre o $\mathrm{K}^{+}$ e outros atributos do solo analisados. 
Pode-se notar a distribuição das observações de cada tratamento, resultado da interação entre os dois componentes principais (Figura 4).

Analisando o eixo 1, referente ao primeiro componente, que relaciona as variáveis ligadas à acidez do solo, verifica-se nítida separação entre dois grandes grupos. Do lado esquerdo da linha vertical que passa pelo zero, encontram-se as observações dos tratamentos T1, T2, T3, T4 e T7; enquanto, do lado direito, estão localizadas as observações dos tratamentos T5, T6, T8 e T9. A análise conjunta do efeito da aplicação de biossólido em variáveis do componente acidez, como $\mathrm{pH}, \mathrm{Ca}^{2+}$ e $\mathrm{Al}^{3+}$, mostra que a influência ocorre a partir da dose de $40 \mathrm{t} \mathrm{ha}^{-1}$, exceto na dose de $40 \mathrm{t} \mathrm{ha}^{-1}$ aplicada superficialmente (T7), que não foi significativamente diferente das menores doses e do tratamento-controle (T1) e adubação mineral (T2). Isso mostra que o poder alcalizante do biossólido, em uma fase inicial após a aplicação, depende da incorporação do material e do contato direto de suas partículas com o meio, pois onde o biossólido foi aplicado superficialmente (T7)

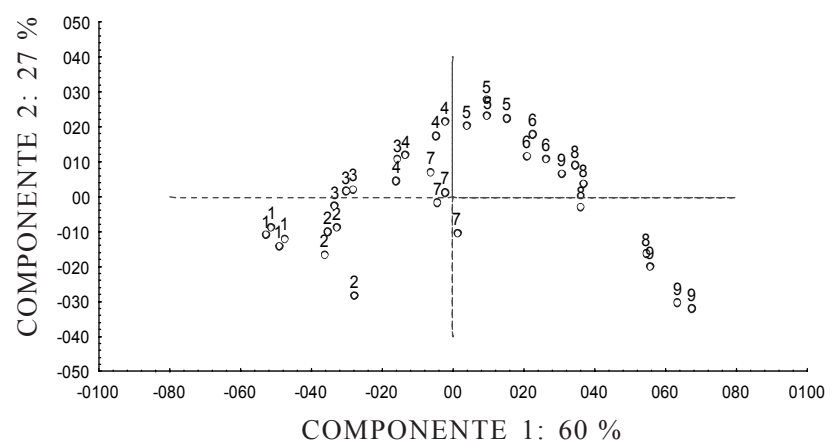

Figura 4. Projeção dos dois componentes principais retidos na análise das onze variáveis do solo, com as variações explicadas por cada componente. $\mathrm{Os}$ números sobre os círculos que representam as observações identificam o tratamento. observaram-se menores valores de $\mathrm{pH}$ e maiores valores de acidez do que onde foi incorporado (T5). A ausência de efeito das doses menores de biossólido, $10 \mathrm{t} \mathrm{ha}^{-1}$ (T3) e $20 \mathrm{t} \mathrm{ha}^{-1}$ (T4), assim como da adubação mineral (T2), sobre a redução da acidez do solo, provavelmente, se deve à intensa lixiviação de íons, diagnosticada pelo aumento da condutividade elétrica e pelos teores dos íons nas águas de drenagem das colunas (dados não apresentados).

Houve uma correlação muito forte do teor de $\mathrm{Ca}^{2+}$ no solo com a soma de bases $(r=0,9998$; $p<0,001)$. Essas duas variáveis contribuíram, de forma semelhante, para a formação dos componentes, participando, de forma equivalente, tanto no primeiro quanto no segundo componente (Quadro 6). A magnitude e o sentido da variação que ocorrem na soma de bases, de acordo com os tratamentos, são os mesmos que ocorrem para o teor de $\mathrm{Ca}^{2+}$. O valor da soma de bases é, praticamente, determinado pelo $\mathrm{Ca}^{2+}$. Esses índices calculados, que são apresentados nos resultados de rotina das análises de solo, podem estar muitas vezes mascarados por alterações drásticas na concentração de apenas um elemento. Trabalhos que avaliam a CTC em solos tratados com biossólido, quando utilizam cálculo para estimativa dessa variável, freqüentemente apresentam valores superestimados pela elevada concentração de Ca no resíduo (Oliveira et al., 2002).

A partir da dose de $40 \mathrm{t} \mathrm{ha}^{-1}$, exceto na aplicação superficial, não é mais observado Al trocável no solo, mostrando reduções de mais de dez vezes em relação ao tratamento-controle (T1), assim como a acidez potencial é reduzida mais de cinco vezes em relação ao solo-controle (Quadro 4).

Comparando o solo que recebeu fertilizantes minerais com o controle, a única variável que apresentou diferença significativa foi o teor de P. Os fertilizantes foram adicionados na forma de sais solúveis, enquanto os nutrientes foram lixiviados através do solo de textura média que se apresentava

Quadro 6. Coeficientes associados a cada variável de fertilidade do solo durante a definição dos componentes principais, após rotação pela variância máxima normalizada.

\begin{tabular}{lccc}
\hline Variável & Componente $\mathbf{1}$ & Componente 2 & Componente 3 \\
\hline $\mathrm{pH} \mathrm{CaCl}{ }_{2}$ & 0,899143 & 0,315739 & 0,222418 \\
$\mathrm{C}$ & $-0,266242$ & 0,890438 & $-0,026210$ \\
$\mathrm{P}$ & 0,445871 & 0,814127 & 0,154962 \\
$\mathrm{~K}^{+}$ & $-0,410007$ & 0,096916 & $-0,887176$ \\
$\mathrm{Ca}^{2+}$ & 0,682298 & 0,699246 & 0,129857 \\
$\mathrm{Mg}^{2+}$ & 0,014472 & 0,804308 & $-0,288139$ \\
$\mathrm{Al}^{3+}$ & $-0,929251$ & 0,032028 & $-0,111714$ \\
$\mathrm{H}+\mathrm{Al}$ & $-0,940657$ & 0,029668 & $-0,258684$ \\
$\mathrm{SB}$ & 0,674666 & 0,710083 & 0,119200 \\
$\mathrm{CTC}$ & 0,318816 & 0,917846 & 0,003054 \\
$\mathrm{~V} \%$ & 0,916613 & 0,284015 & 0,195283 \\
\hline
\end{tabular}


desestruturado pelo peneiramento. $\mathrm{O} \mathrm{K}^{+}$, o $\mathrm{Ca}^{2+} \mathrm{e}$ $\mathrm{Mg}^{2+}$ foram lixiviados e tiveram suas concentrações aumentadas nas águas drenadas das colunas que receberam adubação mineral (dados não apresentados). O P foi o único elemento que não sofreu lixiviação. Normalmente, esse elemento se movimenta pouco no perfil, podendo ter sido, em grande parte, adsorvido no solo. O teor de $\mathrm{P}$ extraível no solo que recebeu biossólido, inclusive onde foi aplicada a menor dose (10 t ha-1), foi significativamente maior do que no solo do tratamento-controle. Houve aumentos progressivos com o aumento da dose, tendo sido, na maior dose (160 t ha-1), o teor de $\mathrm{P}$ quase vinte vezes superior ao determinado no controle (Quadro 4).

Vários autores também detectaram que a aplicação de biossólido foi capaz de aumentar o P extraível no solo (Sui \& Thompson, 2000; Bramryd, 2001; Simonete, 2003). Na dose referência de $40 \mathrm{t} \mathrm{ha}^{-1}$, o tratamento em que o biossólido foi aplicado em superfície (T7) exibiu maior teor médio de P no solo (Quadro 4), em comparação ao tratamento em que o resíduo foi incorporado (T5). É provável que esse efeito seja devido à menor área de contato do biossólido com o solo que recebeu aplicação superficial, daí a menor adsorção do nutriente.

O teor de $\mathrm{Ca}^{2+}$ aumentou com as doses de biossólido até uma aplicação de $80 \mathrm{t} \mathrm{ha}^{-1}$. Não houve diferenças significativas entre os tratamentos na dose referência de $40 \mathrm{t} \mathrm{ha}^{-1}$, nem entre as doses de $80 \mathrm{e}$ $160 \mathrm{t} \mathrm{ha}^{-1}$. Considerando o elevado teor de $\mathrm{Ca}^{2+}$ no biossólido, a partir de $80 \mathrm{t} \mathrm{ha}^{-1}$ pode ter ocorrido uma saturação do complexo de troca por esse elemento.

Nos tratamentos em que foram incorporadas doses de 10, 20 e 40 t ha $^{-1}$ de biossólido, verificou-se uma diminuição do $\mathrm{C}$ orgânico em relação ao solo que recebeu as doses de 80 e $160 \mathrm{t} \mathrm{ha}^{-1}$, bem como tendência de diminuição em relação ao $\mathrm{C}$ orgânico original do solo. Provavelmente, isso deveu-se ao efeito "priming", que trata da diminuição do C do solo logo após uma entrada de material orgânico na área. Terry (1979) também observou a diminuição do $\mathrm{C}$ do solo com a aplicação de biossólido, assim como Hsieh et al. (1981), que relataram a ocorrência do efeito "priming" em estudo sobre a decomposição de lodos de esgoto em condições de laboratório, por meio de medidas do $\mathrm{CO}_{2}$ evoluído.

Normalmente, a maior taxa de decomposição da matéria orgânica do solo, após adição de material orgânico fresco, é atribuída ao incremento da atividade dos microrganismos, em função da disponibilidade de substrato energético. No entanto, Fontaine et al. (2003), após uma análise teórica dos resultados contraditórios encontrados na literatura, chamam a atenção para o fato de ser o mecanismo do efeito "priming" muito mais complexo do que comumente se acredita. Eles discutem um modelo conceitual baseado na competição por nutrientes e energia entre microrganismos especializados (estrategistas r) em decompor matéria orgânica fresca (MOF) e microrganismos generalistas (estrategistas K), que se alimentam principalmente da matéria orgânica polimerizada do solo (MOS). Esse artigo mostra resultados de vários trabalhos em que a adição de nutrientes e $\mathrm{C}$ facilmente assimilável, como açúcares solúveis, aminoácidos, extratos das raízes ou da rizosfera, não altera as taxas de decomposição da MOS. Como a dinâmica da população de estrategistas $K$ é lenta, eles não teriam tempo para aumentar a colônia; já que os estrategistas $r$, que crescem muito rapidamente sobre substratos simples e solúveis, respondem prontamente a uma nova fonte de matéria orgânica lábil e a consomem rapidamente. Por outro lado, o suprimento de C, em forma de componentes mais complexos e insolúveis, pode levar ao efeito "priming" e ao aumento da taxa de decomposição da MOS. Nesse caso, os estrategistas K podem-se beneficiar desse substrato polimerizado que permanece no solo por um tempo mais longo, aumentando sua população e, conseqüentemente, a taxa de decomposição da MOS.

Outro mecanismo proposto pelos autores é que, quando a MOF encontra-se em formas insolúveis, a sua utilização exige uma etapa de despolimerização para produzir componentes assimiláveis. Assim, as próprias enzimas extracelulares produzidas pelos estrategistas r, durante a despolimerização, e liberadas no solo, podem ser eficientes para degradar a MOS. A intensidade desse mecanismo vai depender da diversidade da MOF e de sua similaridade com a MOS.

A capacidade do biossólido em promover aumentos no teor de matéria orgânica no solo vai depender, basicamente, das características do próprio resíduo, da dose, da freqüência e da forma de aplicação (incorporação ou distribuição superficial). Há uma tendência de diminuição do $\mathrm{C}$ do solo com o aumento da dose até $40 \mathrm{t} \mathrm{ha}^{-1}$, que apresenta o menor valor médio do teor de $\mathrm{C}$, sendo cerca da metade do valor do tratamento-testemunha. $\mathrm{Na}$ dose de $40 \mathrm{t} \mathrm{ha}^{-1}$ aplicada superficialmente, não ocorreu o efeito "priming". Com a aplicação superficial, provavelmente, o $\mathrm{C}$ do biossólido que chegou ao solo foi um $\mathrm{C}$ solúvel de fácil assimilação; que, segundo Fontaine et al. (2003), não seria capaz de provocar o efeito "priming". Quando se aplica uma dose muito elevada, por exemplo, $180 \mathrm{t} \mathrm{ha}^{-1}$, o potencial de $\mathrm{C}$ que é introduzido no ecossistema seria capaz de, mesmo ocorrendo uma diminuição da matéria orgânica original do solo, aumentar o teor de $\mathrm{C}$ detectado na análise e manter esse aumento por um período maior. Harrison et al. (1994) observaram, em Washington nos EUA, aumentos de 1,8 vez no teor de $\mathrm{C}$ do solo, quinze anos após a aplicação de 500 t ha-1 de biossólido e plantio de três espécies florestais. Os autores encontraram uma retenção líquida do $\mathrm{C}$ adicionado da ordem de $67 \%$ nos primeiros $27 \mathrm{~cm}$ do perfil. 


\section{Nutrição do eucalipto}

Em relação à nutrição das mudas de eucalipto, a análise dos componentes principais permitiu a definição de cinco componentes. Os cinco componentes principais retidos na análise explicaram $89 \%$ da variação total existente nos dados, considerando a variância acumulada (Quadro 8).

A avaliação dos coeficientes das variáveis originais para cada componente identifica quais nutrientes apresentam o mesmo padrão de variação, dependendo dos tratamentos aplicados, e quais nutrientes foram significativos na definição dos componentes (Quadro 9).

O primeiro componente relacionou os macronutrientes $\mathrm{N}, \mathrm{P}$ e S e pode ser interpretado como sendo resultante da interação entre nutrientes, cuja extração pelas plantas encontra-se relacionada com a taxa de mineralização e com o teor de matéria orgânica do solo, principal fonte da disponibilidade desses nutrientes no solo. Esse componente explica $47 \%$ da variância, tendo os elementos N, P e S apresentado o mesmo padrão de variação entre os tratamentos, aumentando seus teores nas folhas do eucalipto com a aplicação das maiores doses de biossólido. O segundo componente explicou $18 \%$ da variância e relacionou, de maneira inversa, os macronutrientes $\mathrm{K}$ e $\mathrm{Mg}$, refletindo a diminuição do teor de $\mathrm{Mg}$ com a aplicação do biossólido, provavelmente por causa da competição com outros cátions durante o processo de absorção. Os demais componentes (3, 4 e 5) tiveram pequeno efeito na variância explicada, mas detectaram alguma influência dos micronutrientes B, Zn, Mn e Fe na definição da variação entre os tratamentos. Os micronutrientes B e Zn, que são importantes para a cultura de eucalipto, apresentaram tendências de aumento em seus teores foliares em alguns tratamentos com aplicação de biossólido, tendo o B apresentado diferenças significativas entre o T9, onde foi aplicada a maior dose do resíduo, e o tratamentotestemunha (T1) e adubação mineral (T2) (Quadro 7).

$\mathrm{Na}$ figura 5, pode-se observar como a projeção mútua dos dois principais componentes determina a distribuição das observações de cada tratamento. As plantas que receberam 10 e $20 \mathrm{t} \mathrm{ha}^{-1}$ de biossólido (T3 e T4) apresentaram teor de $\mathrm{K}$ nas folhas mais elevado e teor de $\mathrm{Mg}$ mais baixo do que as plantas que receberam os outros tratamentos (Quadro 7).

Analisando o eixo 1, referente ao primeiro componente, do lado direito e mais distante da linha vertical que passa pelo zero, encontram-se as observações dos tratamentos T8 e T9, mostrando o efeito positivo desses tratamentos sobre os teores de N, P e S nas folhas do eucalipto. Do lado esquerdo do eixo vertical, encontram-se todas as observações do T1 ao T4, mostrando que a aplicação da adubação mineral e de até $20 \mathrm{t} \mathrm{ha}^{-1}$ de biossólido não surtiu efeito sobre esses nutrientes, que tiveram valores semelhantes aos do tratamento-testemunha.

Quadro 7. Em negrito, valores médios $(n=4)$ dos teores dos nutrientes nas folhas do eucalipto colhido aos doze meses conforme a variação nos tratamentos (TT). Abaixo da média, encontram-se os valores dos intervalos calculados com $95 \%$ de confiança

\begin{tabular}{|c|c|c|c|c|c|c|c|c|c|c|c|}
\hline & $\mathbf{N}$ & $\mathbf{P}$ & $\mathbf{K}^{+}$ & $\mathrm{Ca}^{2+}$ & $\mathrm{Mg}^{2+}$ & $\mathbf{S}$ & $\mathrm{Fe}$ & $\mathrm{Cu}$ & $\mathrm{Zn}$ & Mn & B \\
\hline & & & $\mathrm{g} \mathrm{k}$ & & & & & & $\mathrm{mg} \mathrm{kg}^{-1}$ & & \\
\hline \multirow[t]{2}{*}{$\mathrm{T} 1$} & 10,5 & 0,8 & 6,4 & 10,1 & 3,7 & 1,3 & 37 & 8 & 58 & 642 & 23 \\
\hline & $8,9-12,0$ & $0,7-1,0$ & $3,4-9,3$ & $5,5-14,7$ & $2,3-5,1$ & $1,2-1,5$ & $30-44$ & $6-10$ & $34-81$ & 353-932 & $19-27$ \\
\hline \multirow[t]{2}{*}{$\mathrm{T} 2$} & 9,3 & 1,1 & 5,6 & 10,4 & 4,3 & 1,1 & 27 & 7 & 51 & 739 & 25 \\
\hline & $7,2-11,4$ & $0,5-1,6$ & $4,7-6,4$ & $7,7-13,2$ & $3,5-5,1$ & $1,0-1,2$ & $20-35$ & $4-10$ & $48-53$ & $556-921$ & $18-32$ \\
\hline \multirow[t]{2}{*}{$\mathrm{T} 3$} & 9,6 & 1,0 & 11,4 & 13,8 & 2,2 & 1,2 & 29 & 11 & 60 & 408 & 38 \\
\hline & $7,9-11,2$ & $0,7-1,2$ & $7,9-14,8$ & $9,3-18,3$ & $2,0-2,4$ & $0,7-1,8$ & $28-30$ & $8-13$ & $44-75$ & $315-500$ & $27-50$ \\
\hline \multirow[t]{2}{*}{$\mathrm{T} 4$} & 9,2 & 0,8 & 7,5 & 17,4 & 2,7 & 1,2 & 28 & 9 & 52 & 348 & 34 \\
\hline & $7,7-10,6$ & $0,7-0,8$ & $6,1-8,9$ & $13,8-21,0$ & $2,2-3,2$ & $0,9-1,5$ & $25-32$ & $8-11$ & $34-69$ & $-9-705$ & $20-49$ \\
\hline \multirow[t]{2}{*}{$\mathrm{T} 5$} & 10,4 & 1,1 & 5,9 & 34,3 & 3,3 & 1,7 & 33 & 13 & 70 & 282 & 42 \\
\hline & $9,2-11,5$ & $0,7-1,5$ & $4,2-7,6$ & $19,0-49,6$ & $2,8-3,8$ & $0,8-2,5$ & $27-38$ & $11-15$ & $48-91$ & $100-463$ & $18-66$ \\
\hline \multirow[t]{2}{*}{$\mathrm{T} 7$} & 9,8 & 1,0 & 5,7 & 16,9 & 3,4 & 1,8 & 36 & 11 & 61 & 481 & 35 \\
\hline & $8,9-10,6$ & $0,7-1,2$ & $3,9-7,4$ & $11,7-22,1$ & $2,2-4,5$ & $1,2-2,3$ & $34-38$ & $8-14$ & $50-72$ & $224-738$ & $23-46$ \\
\hline \multirow[t]{2}{*}{$\mathrm{T} 8$} & 14,0 & 1,4 & 5,4 & 24,3 & 3,0 & 2,6 & 34 & 13 & 92 & 203 & 37 \\
\hline & $11,8-16,3$ & $1,2-1,7$ & $4,8-6,0$ & $13,3-35,4$ & $2,4-3,7$ & $1,8-3,4$ & $32-37$ & $10-17$ & $71-112$ & $41-365$ & $19-55$ \\
\hline \multirow[t]{2}{*}{ T9 } & 17,1 & 1,7 & 5,6 & 24,2 & 3,5 & 3,0 & 34 & 16 & 73 & 214 & 48 \\
\hline & $14,0-20,1$ & $1,6-1,8$ & $5,0-6,1$ & $19,0-29,4$ & $3,0-4,1$ & $1,8-4,1$ & $29-40$ & $11-20$ & $51-94$ & $128-301$ & $32-63$ \\
\hline
\end{tabular}

Tratamentos: T1-testemunha; T2-adubação mineral; T3-10 t ha ${ }^{-1}$ de biossólido + K mineral; T4-20 t ha-1 de biossólido + K mineral; T5-40 t ha ${ }^{-1}$ de biossólido + K mineral; T7-40 t ha ${ }^{-1}$ de biossólido $+\mathrm{K}$ mineral, aplicação superficial; T8-80 t ha ${ }^{-1}$ de biossólido; T9-160 t ha ${ }^{-1}$ de biossólido. 
Analisando o segundo componente, verifica-se maior efeito das observações dos tratamentos T3 e T4, localizadas mais acima da linha horizontal, na definição do efeito sobre os nutrientes $\mathrm{K} \mathrm{e} \mathrm{Mg}$, variáveis significativas na formação do segundo componente. $\mathrm{O}$ teor de $\mathrm{K}$ foi significativamente maior nas folhas das plantas que receberam $10 \mathrm{t} \mathrm{ha}^{-1}$

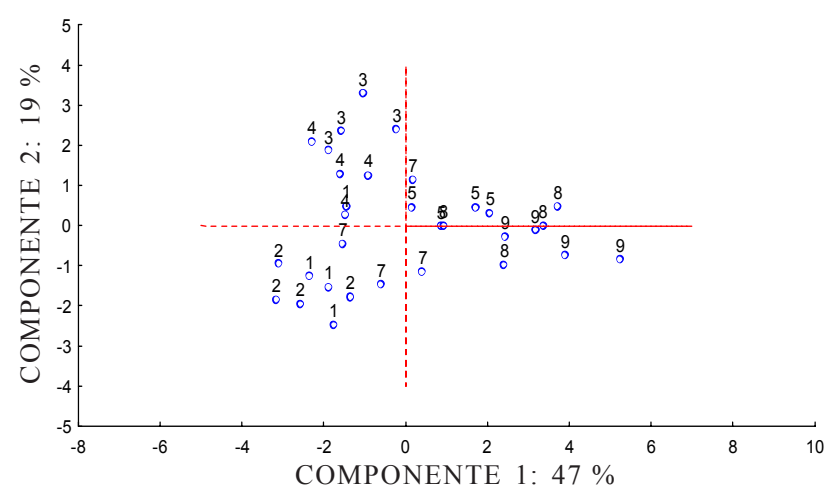

Figura 5. Projeção dos dois componentes principais retidos na análise dos onze nutrientes nas folhas dos eucaliptos, com as variações explicadas por cada componente. Os números sobre as observações identificam o tratamento. de biossólido, cujo tratamento foi também o que recebeu maior quantidade de $\mathrm{K}$ mineral na complementação. Esta mesma dose proporcionou menores valores de Mg. Também houve tendência de diminuição dos teores de $\mathrm{Mg}$ nas folhas das plantas que receberam doses maiores de biossólido em relação à testemunha e à adubação mineral (Quadro 7).

A aplicação de 80 e 160 t ha $^{-1}$ de biossólido proporcionou aumentos significativos dos teores foliares de N, P e S. O teor foliar mais elevado de $\mathrm{Ca}$ foi encontrado nas folhas do eucalipto que recebeu $40 \mathrm{t} \mathrm{ha}^{-1}$ de biossólido. Tal como observado para a maioria dos atributos do solo, não houve diferenças entre as doses de 80 e 160 t ha $^{-1}$, ou seja, o adicional de Ca aplicado via maior dose de biossólido não se refletiu em aumento do teor foliar do elemento, provavelmente, por causa da saturação do complexo de troca do solo. Apesar dos elevados teores de Fe e Zn no biossólido, não houve diferenças significativas das concentrações desses elementos nas folhas das plantas cultivadas nos diferentes tratamentos. O teor de Mn diminuiu com o aumento das doses de biossólido.

Guedes \& Poggiani (2003) encontraram comportamentos semelhantes em eucalipto

Quadro 8. Autovalores e proporção da variância total explicada pelos cinco componentes principais originados dos onze nutrientes analisados nas folhas dos eucaliptos

\begin{tabular}{ccccc}
\hline Componente & Autovalor & Autovalor acumulado & Variância explicada & Variância acumulada \\
\hline 1 & 5,217018 & 5,217018 & 47,42744 & 47,42744 \\
2 & 2,032549 & 7,249567 & 18,47772 & 65,90516 \\
3 & 0,910350 & 8,159917 & 8,27591 & 74,18107 \\
4 & 0,877085 & 9,037002 & 7,97350 & 82,15456 \\
5 & 0,801121 & 9,838124 & 7,28292 & 89,43749 \\
\hline
\end{tabular}

Quadro 9. Coeficientes associados a cada nutriente foliar durante a definição dos componentes principais

\begin{tabular}{lccccc}
\hline Variável & Componente 1 & Componente 2 & Comporente 8 & Componente 4 & Comporente 5 \\
\hline N & 0,904588 & 0,086630 & 0,197065 & 0,215851 & 0,171504 \\
F & 0,894599 & 0,161037 & $-0,042926$ & 0,240416 & 0,165006 \\
K & $-0,096527$ & 0,839524 & $-0,071884$ & $-0,012144$ & $-0,332697$ \\
$\mathrm{Ca}$ & 0,166499 & 0,099093 & 0,067950 & 0,836769 & 0,406565 \\
$\mathrm{Mg}$ & 0,112954 & $-0,932711$ & 0,028506 & $-0,073483$ & $-0,246230$ \\
$\mathrm{~S}$ & 0,826656 & 0,035845 & 0,281320 & 0,221469 & 0,323034 \\
$\mathrm{~B}$ & 0,188770 & 0,081780 & 0,962668 & 0,106798 & 0,067847 \\
$\mathrm{Cu}$ & 0,643387 & $-0,104602$ & 0,112230 & 0,609621 & 0,242069 \\
$\mathrm{Fe}$ & 0,309826 & 0,115340 & 0,126717 & 0,162146 & 0,774566 \\
$\mathrm{Mn}$ & $-0,421690$ & 0,476353 & 0,090899 & $-0,240756$ & $-0,622875$ \\
$\mathrm{Zn}$ & 0,369361 & $-0,175289$ & 0,087265 & 0,859603 & $-0,060193$ \\
Total & 3,211469 & 1,907864 & 1,101675 & 2,065386 & 1,551731 \\
\hline
\end{tabular}


fertilizado com o mesmo biossólido, cultivado em condições de campo e avaliado dos seis aos catorze meses após o plantio. Os autores também observaram aumentos nos teores de $\mathrm{Ca}, \mathrm{N}, \mathrm{P}$ e S e diminuição nos teores de $\mathrm{Mn}$ e $\mathrm{Mg}$ nas folhas das plantas cultivadas com biossólido, provavelmente em virtude da inibição competitiva do elemento Ca. Os autores chamam a atenção para o fato de que a diminuição da extração de Mn e Mg pelas plantas de eucalipto não prejudica a cultura, já que ela, na maioria das vezes, não apresenta respostas significativas à aplicação de Mn, sendo mais comum a ocorrência de toxidez, e apresenta tolerância a relações Ca/Mg bastante amplas. Silva et al. (1998), trabalhando com lodo procedente da mesma estação de tratamento, também observaram que o biossólido proporcionou aumento da disponibilidade dos nutrientes no solo, principalmente, $\mathrm{P}, \mathrm{S}$ e $\mathrm{Ca}^{2+}$, e, conseqüentemente, maior absorção pelas plantas.

\section{Relação solo/planta}

As relações entre os componentes principais que representam as variáveis ligadas à fertilidade do solo e os componentes que representam os nutrientes nas folhas do eucalipto podem ser observadas no quadro 10. Verifica-se que o C2 do solo apresentou correlação altamente significativa $(p<0,001)$ com $o$ C1 da planta, assim como o C1 do solo com o C5 da planta $(\mathrm{p}<0,001)$.

A correlação entre o C2 do solo e o C1 da planta representa a relação entre a CTC e o C orgânico do solo (variáveis com maiores coeficientes no $\mathrm{C} 2$ solo) e os nutrientes N, P e S absorvidos pelas mudas de eucalipto (C1 planta). Apenas as doses de 80 e $160 \mathrm{t} \mathrm{ha}^{-1}$ proporcionaram aumentos significativos dos teores de N, P e S nas folhas das plantas (Quadro 7) e aumento do teor de C orgânico do solo (Quadro 4). A concentração desses elementos na solução do solo e a conseqüente disponibilidade para absorção pelas plantas estão diretamente relacionadas com a dinâmica de decomposição do material orgânico aplicado e com a mineralização da matéria orgânica original do solo.
As correlações do $\mathrm{C} 1$ solo com o $\mathrm{C} 4$ planta e com o C5 planta indicam que a acidez do solo (C1 solo) variou em consonância com os teores de $\mathrm{Ca}, \mathrm{Cu}$ e Zn (C4 planta) e com os teores de Fe e Mn (C5 planta) nas folhas do eucalipto. O coeficiente do $\mathrm{Mn}$ na formação do componente foi negativo (Quadro 9), mostrando que seu teor nas plantas variou de maneira inversa com a acidez do solo. O teor de $\mathrm{Mn}$ diminuiu com o aumento das doses de biossólido e com o aumento do pH (Figura 6). A diminuição do teor de Mn com o aumento da dose de biossólido pode ser considerada benéfica para o eucalipto. $\mathrm{O}$ nível crítico desse elemento é de $675 \mathrm{mg} \mathrm{kg}^{-1}$ (Wadt \& Novais, 1997), e abaixo desse valor não é detectada deficiência, podendo, no entanto, ocorrer problema de excesso e toxidez para valores maiores.

Anjos \& Mattiazzo (2000), trabalhando com o mesmo tipo de biossólido utilizado nesse experimento, também detectaram menores teores de Mn em plantas de milho tratadas com o resíduo. Tsadilas et al. (1995) verificaram que as concentrações de Fe e Mn no solo, extraídos por DTPA, foram reduzidas com aplicação de biossólido, mostrando uma forte correlação negativa com o pH. Outros autores

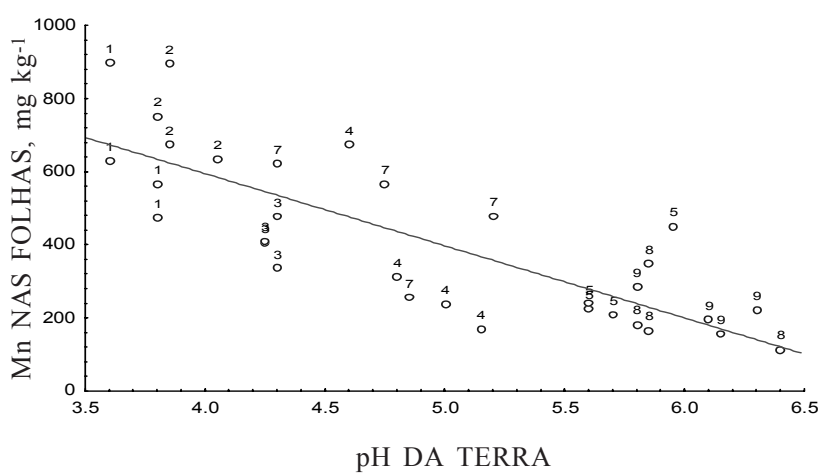

Figura 6. Correlação entre os valores de pH da terra e os teores de Mn nas folhas das plantas de eucalipto $(r=0,81$ e $p<0,001)$. Os números sobre as observações identificam o tratamento.

Quadro 10. Análise de correlação entre os "scores" dos componentes ligados à fertilidade do solo e os "scores" dos componentes formados pelos nutrientes nas folhas do eucalipto, retidos na análise de componente principal

\begin{tabular}{lrrrrr}
\hline & C1 planta & C2 planta & C3 planta & C4 planta & C5 planta \\
\hline C1 solo & $\begin{array}{r}0,329 \\
\mathrm{p}=0,066\end{array}$ & $\mathrm{p}=0,077$ & $\mathrm{p}=0,383$ & $\mathbf{p}=\mathbf{0 , 0 0 7}$ & $\mathbf{0 , 6 3 5}$ \\
& & & & $\mathbf{0 , 4 0 , 0 0 1}$ \\
C2 solo & $\mathbf{0 , 7 1 0}$ & 0,466 & 0,167 & 0,023 & $-0,090$ \\
& $\mathbf{p}<\mathbf{0 , 0 0 1}$ & $\mathrm{p}=0,007$ & $\mathrm{p}=0,362$ & $\mathrm{p}=0,899$ & $\mathrm{p}=0,623$ \\
C3 solo & $-0,007$ & $-0,288$ & $-0,326$ & $-0,254$ & $-0,284$ \\
& $\mathrm{p}=0,972$ & $\mathrm{p}=0,110$ & $\mathrm{p}=0,069$ & $\mathrm{p}=0,161$ & $\mathrm{p}=0,116$ \\
\hline
\end{tabular}


também relataram a deficiência de Mn em plantas e, ou, diminuição do teor de Mn trocável em solos fertilizados com biossólido, associada à elevação do $\mathrm{pH}$ na terra que recebeu o resíduo (Sloan \& Basta, 1995; Christie et al., 2001; Guedes \& Poggiani, 2003).

\section{CONCLUSÕES}

1. Os resultados obtidos permitem concluir que a aplicação de biossólido alcalino melhora as propriedades químicas do solo, diminuindo a acidez e aumentando a disponibilidade da maioria dos nutrientes. A utilização de biossólido propicia aumento dos teores foliares de $\mathrm{Ca}, \mathrm{N}, \mathrm{P}, \mathrm{S}$ e a diminuição dos teores de Mn e Mg, em plantas jovens de eucalipto.

2. O biossólido alcalino pode ser utilizado como material corretivo da acidez do solo e como fonte de vários elementos para a nutrição de eucalipto.

3. A utilização de até $40 \mathrm{t} \mathrm{ha}^{-1}$ de biossólido não causa efeito condicionador de solo até um ano após a disposição, pois a incorporação do material pode diminuir o teor de C orgânico do solo logo após a aplicação de menores doses de biossólido.

\section{AGRADECIMENTOS}

Ao pesquisador Jean-Paul Laclau, pela leitura do artigo e pelos preciosos comentários; à Companhia de Saneamento do estado de São Paulo (SABESP), pelo financiamento da pesquisa.

\section{LITERATURA CITADA}

ANDRADE, C.A. Nitratos e metais pesados em solos e plantas de Eucalyptus grandis após aplicação de biossólido da ETE Barueri. Piracicaba, Escola Superior de Agricultura "Luiz de Queiroz", 1999. 65p. (Tese de Mestrado)

ANJOS, A.R.M. \& MATTIAZZO, M.E. Metais pesados em plantas de milho cultivadas em Latossolos repetidamente tratados com biossólido. Sci. Agric., 57:1-16, 2000.

BETTIOL, W. \& CARVALHO, P.C.T. Utilização de lodo de esgoto primário e fertilizante organo-mineral IPT na cultura do milho. Fertilizantes, 44:14-15, 1982.

BRAMRYD, T. Effects of liquid and dewatered sewage sludge applied to a Scots pine stand (Pinus sylvestris L.) in central Sweden. For. Ecol. Manag., 147:197-216, 2001.

CHRISTIE, P.; EASSON, D.L.; PICTON, J.R. \& LOVE, S.C.P. Agronomic value of alkaline-stabilized sewage biosolids for spring barley. Agron. J., 93:144-151, 2001.
CORRÊA, R.S. \& CORRÊA, A.S. Valoração de biossólidos como fertilizantes e condicionadores de solos. SANARE, 16:49-56, 2001.

DAHLIM, S.; WITTER, E.; MART, A.; TURNER, A. \& BAATH, E. Where's the limit? Changes in the microbiological properties of agricultural soils at low levels of metal contamination. Soil Biol. Biochem., 29:1405-1415, 1997.

DOWDY, R.H.; LATTERELL, J.J.; HINESLEY, T.D.; GROSSMAN, R.B. \& SULLIVAM, D.L. Trace metal movement in an Aeric Ochraqualf following 14 years of annual sludge applications. J. Environ. Qual., 20:119-123, 1991.

EATON, A.D.; CLESCERI, L.S. \& GREENBERG, A.E., eds. Standard methods for the examination of water and wastewater. 19.ed. Washington D.C., American Public Health Association, 1995. 953p.

El-BAHA A.M. Growth response of Eucalyptus camaldulensis as affected by thinning and sewage sludge or inorganic fertilizer on a poor quality site. Alexandria J. Agric. Res., 46, 2001 (Tree CD Abstract)

FONTAINE, F.; MARIOTTI, A. \& ABBADIE, L. The priming effect of organic matter: A question of microbial competition? Soil Biol. Biochem., 35:837-843, 2003.

GUEDES, M.C. \& POGGIANI, F. Variação dos teores de nutrientes foliares em eucalipto fertilizado com biossólido. Sci. For., 63:188-201, 2003.

HARRISON, R.; XUE, D.; HENRY, C. \& COLE, D.W. Longterm effects of heavy applications of biosolids on organic matter and nutrient content of a coarse-texture forest soil. For. Ecol. Manag., 66:165-177, 1994.

HART, J.B.; NGUYEN, P.V.; URIE, D.H. \& BROCKWAY, D.G. Silvicultural use of wastewater sludge. J. For., 86:17-24, 1988

HENRY, C.L.; COLE, D.W.; HARRISON, R.B.; BENGTSSON, J. \& LUNDKVIST, H. Use of municipal sludge to restore and improve site productivity in forestry: The Packe Forest Sludge Research Program. For. Ecol. Manag., $66: 137-49,1994$

HENRY, C.L.; COLE, D.W.; HINCKLEY, T.M. \& HARRISON, R.B. The use of municipal and pulp paper sludges to increase production in forestry. J. Sustain. For., 1:41-45, 1993.

HSIEH, Y.P.; LOWELL, A.D. \& MOTTO, H.M. Modeling sewage sludge decomposition in soil: I. Organic carbon transformation. J. Environ. Qual., 10:54-64, 1981.

KAPOSTS, V.; KARINS, Z. \& LAZDINS, A. Use of sewage sludge in forest cultivation. Baltic For., 6:24-28, 2000.

LEONARD, P. \& McKINNEY, B. Biosolids application to forests - Implementation and operations. In: THE FOREST ALTERNATIVE. PRINCIPLES AND PRACTICE OF RESIDUALS USE. INTERNATIONAL SYMPOSIUM IN UNIVERSITY OF WASHINGTON CAMPUS. Seattle, 1997. Proceedings, Seattle, 1997.

MALAVOLTA, E.; VITTI, E.C. \& OLIVEIRA, S.A. Avaliação do estado nutricional das plantas (princípios e aplicações). 2.ed. Piracicaba, Associação Brasileira para Pesquisa da Potassa e do Fosfato, 1997. 319p. 
MATTHEWS, P. Sustainability in biosolids management. Water Sci. Techn., 38:97-102, 1998.

McNAB, W.H. \& BERRY, C.R. Distribution of aboveground in three pine species planted on a devasted site amended with sewage sludge or inorganic fertilizer. For. Sci., 31:373-382, 1985.

MELO, W.J.; MARQUES, M.O. \& MELO, V.P. O uso agrícola do biossólido e as propriedades do solo (289-363). In: Biossólidos na agricultura. TSUTIYA, M.T.; COMPARINI, J.B.; SOBRINHO, P.A.; ESPANHOL, I.; CARVALHO, P.C.T.; MELFI, A.J.; MELO, W.J. \& MARQUES, M.O., eds. São Paulo, SABESP, 2001. p.289-292.

OLIVEIRA, F.C.; MATTIAZZO, M.E.; MARCIANO, C.R. \& ROSSETO, R. Efeitos de aplicações sucessivas de lodo de esgoto em um Latossolo Amarelo distrófico cultivado com cana-de-açucar: Carbono orgânico, condutividade elétrica, pH e CTC. R. Bras. Ci. Solo, 26:505-519, 2002.

PHILLIPS, R.P.; FISHER, J.T. \& MEXAL, J.G. Fuelwood production utilizing Pinus eldarica and sewage sludge fertilizer. For. Ecol. Manag., 16:95-102, 1986.

POGGIANI, F. \& BENEDETTI, V. Aplicabilidade do lodo de esgoto urbano em plantações de eucalipto. Silvicultura, 80:48-52, 1999.

POLGLASE, P.J. \& MYERS, B.J. Tree plantation for recycling effluent and biosolids in Australia. In: ELDRIDGE, K.G., ed. ENVIRONMENTAL MANAGEMENT: The role of eucalypts and other fast growing species, 1995. Proceedings of the Workshop held in Australia, 1995. p.100-109.

RAIJ, B. van; QUAGGIO, J.A.; CANTARELLA, H.; FERREIRA, M.E.; LOPES, A.S. \& BATAGLIA, O.C. Análise química do solo para fins de fertilidade. Campinas, Fundação Cargill, 1987. 170p.

SILVA, F.C.; BOARETO, A.E.; BERTON, R.S.; ZOTELLI, H.B.; PEIXE, C.A. \& MENDONÇA, E. Cana de açucar cultivada em solo adubado com biossólido. Pesq. Agropec. Bras., 33:1-8, 1998.

SIMONETE, M.A.; KIEHL, J.C.; ANDRADE, C.A. \& TEIXEIRA, C.F.A. Efeito do lodo de esgoto em um Argissolo e no crescimento e nutrição de milho. Pesq. Agropec. Bras., 38:1187-1195, 2003.
SLOAN, J.J. \& BASTA, N.T. Remediation of acid soils by using alkaline biosolids. J. Environ. Qual., 24:1097-1103, 1995.

SMITH, C.T. \& CARNUS, J.M. Biosolids - planning and design. In: The forest alternative. Principles and practice of residuals use. INTERNATIONAL SYMPOSIUM ON THE USE OF RESIDUALS AS SOIL AMENDMENTS IN FOREST ECOSYSTEMS. Seattle, 1997. Proceedings. Seattle, University of Washington, 1997. p.45-52.

SOARES, M.T.S. Taxas de mineralização e de lixiviação do nitrogênio, e alterações da fertilidade de um Latossolo Vermelho-Amarelo degradado e outro não-degradado fertilizados com biossólido e florestados com Eucalyptus grandis. Piracicaba, Escola Superior de Agricultura "Luiz de Queiroz", 2003. 142p. (Tese de Doutorado)

SUI, Y. \& THOMPSON, M.L. Phosphorus sorption, desorption, and buffering capacity in a biosolids-amended mollisol. Soil Sci. Soc. Am. J., 64:164-169, 2000.

TERRY, R.E.; NELSON, D.W. \& SOMMERS, L.E. Carbon cycling during sewage sludge decomposition in soils. Soil Sci. Soc. Am. J., 43:494-499, 1979.

TSADILAS, C.D.; MATSI, T.; BARBAYANNIS, N. \& DIOMOYANNIS, D. Influence of sewage sludge application on soil properties and on the distribution and availability of heavy metal fractions. Comm. Soil Sci. Plant Anal., 26:2603-2619, 1995.

VAZ, L.M.S. \& GONÇALVES, J.L.M. Uso de biossólidos em povoamento de eucalipto: Efeito em atributos químicos do solo, no crescimento e na absorção de nutrientes. R. Bras. Ci. Solo, 26:747-758, 2002.

WADT, P.G.S. \& NOVAIS, R.F. Influência da idade da árvore na interpretação do estado nutricional de Eucalyptus grandis, pelos métodos do nível crítico e do DRIS. In: IUFRO CONFERENCE ON SILVICULTURE AND IMPROVEMENT TO EUCALYPT. Salvador, 1997. Proceedings. Colombo, Embrapa, 1997. p.262-268.

WEETMAN, G.F.; McDONALD, M.A.; PRESCOTT, C.E. \& KIMMINS, J.P. Responses of Western hernlock, Pacific silver fir and Western red cedas plantations ou Northen Vancouver Island to applications of sewage sludge and inorganic fertilizer. Can. J. For. Res., 23:1815-1820, 1993. 